\title{
Cultura y paisaje en la política turística del primer franquismo $(1939-1956)^{*}$
}

\section{Culture and landscape in the Spanish tourism policy during first francoism (1939-1956)}

\author{
Isabel del Río Lafuente ${ }^{1}$
}

\begin{abstract}
RESUMEN
El gobierno de Franco utilizó el turismo durante los primeros años de la Dictadura como instrumento de política cultural nacionalista y de propaganda para la legitimación del régimen. El texto, en el marco de una cultura nacional-católica de ideología falangista, analiza la política turística en sus diversas manifestaciones, cultural, de ocio, de vacaciones, religiosa, de naturaleza, de interior o de costa, puesta en práctica desde 1939 a 1956 y relaciona esta práctica turística con los territorios y los paisajes nacionales que se eligen para ser visitados por su adecuación a los intereses políticos del momento. El método utilizado deriva de la selección e interpretación de documentación del momento y de textos bibliográficos que analizan aspectos de la política, la cultura y el turismo de la etapa analizada.
\end{abstract}

PAlabras Clave: España; primer franquismo; política cultural; política turística; paisajes turísticos.

\section{ABSTRACT}

The Franco government used the tourism during the early years of the dictatorship as an instrument of nationalist cultural politics and propaganda to legitimize the regime.

\footnotetext{
* Este trabajo se ha realizado dentro del Proyecto de Investigación "La valoración patrimonial e identitaria del paisaje en España (1875-2010): claves geográficas, culturales y políticas", CSO2012-38425, financiado por el Ministerio de Economía y Competitividad.

1 Departamento de Geografía Humana de la Universidad Complutense de Madrid, iriolafu@ghis.ucm.es.
} 
The text, as part of a national catholic culture Falangist ideology, analyzes the tourism policy in its various manifestations, cultural, leisure, holiday, religious, nature, interior or coast, implemented since 1939 to 1956 and relates this tourist practice national territories and landscapes that are chosen to be visited by its relevance to the political interests of the moment. The method used is derived from the selection and interpretation of documentation and bibliographic text when analyzing aspects of politics, culture and tourism in the analyzed period.

KEY WORDS: Spain; first francoism; cultural policy; tourism policy; tourism landscape.

\section{INTRODUCCIÓN}

El estudio dinámico de las relaciones entre la cultura, la política y el turismo a lo largo del siglo veinte y principios del veintiuno en España está suscitando en los últimos años una línea de investigación con diversas ramificaciones en la que participan, sobre todo, historiadores, politólogos, sociólogos, economistas, geógrafos y estudiosos de la información y la comunicación social, que está dando lugar a análisis donde predomina la orientación histórico-cronológica de alguna de las tres dimensiones o los análisis que muestran de forma integrada las relaciones que se dan entre la cultura, la política y el turismo. Con un enfoque generalista centrado en la historia del turismo en España y sus implicaciones económicas destacan, entre otros, el trabajo colectivo dirigido por Fernando Bayón Mariné (Bayón, 1999), el de Ana Moreno García (Moreno, 2007) y el de Rafael Vallejo Pousada (Vallejo, 2014); entre los trabajos también generalistas que analizan de manera monográfica la política turística española están los de Carmelo Pellejero Martínez (Pellejero, 2002; 2004) y María Velasco González (Velasco, 2004; 2005); y como trabajo ilustrativo donde se analiza de forma dinámica las relaciones entre cultura, turismo y política destaca el estudio de Sasha D. Pack (Pack, 2009). En todos estos casos, se utiliza la visión histórico-cronológica a través del establecimiento de una serie de etapas, diferenciables en la trayectoria del turismo español contemporáneo, cuya datación viene a ser muy semejante en todos ellos. Unas veces, estas etapas las define la permanencia del principal organismo oficial responsable del turismo en cada momento, que además les da nombre (Pellejero, 1999; Velasco, 2004); otras veces, es la evolución política y técnica el factor diferenciable (Bayón, 1999; Pack, 2009), lo que permite numerarlas pero, sobre todo, calificarlas por su significado. El presente trabajo analiza los hechos entre 1939 y 1956, tiempo que genéricamente se considera como el primer franquismo y en el que Pack diferencia dos sub-etapas, 
la de 1939-1945 en la que «empieza el franquismo» y la de 1945-1957 o «levantando las barreras» 2 .

Junto a los estudios diacrónicos sobre la evolución de la cultura, el turismo y la política turística en la etapa del primer franquismo, destacan por su nivel interpretativo los análisis monográficos centrados en alguno de los aspectos que aquí interesan. Así están las obras de Beatriz Correyero y María Rosa Cal que tratan sobre el turismo como propaganda de Estado (Correyero, 2003; 2004; Cal y Correyero, 2008), los trabajos de Francisco Sevillano Calero sobre cultura, propaganda y medios de comunicación (Sevillano Calero, 1998; 2002) y la tesis de Jesús Ferrer Cayón sobre La instrumentalización política de la cultura durante el primer franquismo, leída en 2012 en la Universidad de Cantabria (Ferrer Cayón, 2012).

Partiendo de las aportaciones señaladas sobre el tema, el texto intenta avanzar en la interpretación de la política turística en sus diversas manifestaciones, cultural, de ocio, de vacaciones, religioso, de naturaleza, de interior o de costa, puesta en práctica desde 1939 a 1956 y relaciona esta práctica turística con los territorios y los paisajes nacionales que se eligen para ser visitados por su adecuación a los intereses políticos del momento. El estudio se realiza teniendo en cuenta el marco de la cultura nacional-catolicista de ideología falangista impuesta por el nuevo Régimen y el método utilizado deriva de la selección e interpretación de documentación del momento y de textos bibliográficos que analizan aspectos de la política, la cultura y el turismo de la etapa analizada.

\section{Marco CUltural de la POlítica turística, 1939-1956}

Durante los tres años de la Guerra Civil Española, tiempo inmediatamente anterior al comienzo de la etapa que aquí se analiza, convivieron dos prácticas turísticas, ambas con fuerte orientación política y propagandística donde podían compararse dos modos culturales de entender el turismo y la práctica turística. Hemos señalado en otro lugar (Brandis y Rio, 2016) que, mientras que en la España republicana, el Ministerio de Cultura y el Patronato Nacional de Turismo continuaron a pesar de las dificultades con algunas de sus funciones principales como eran las de dar a conocer los valores culturales, patrimonia-

${ }^{2}$ El trabajo de Sasha D. Pack nombra y califica las etapas que conforman la evolución del turismo en España de la siguiente manera: «los siglos XviI y XIx: la modernización»; «19391945: empieza el franquismo»; «1945-1957: levantando las barreras»; «1957-1962: el gran asalto»; «1962-1969: desarrollo y aguas revueltas»; «1975: empieza otra era» (Pack, 2009: 7-8). 
les y paisajísticos del país, en la España sublevada, el Servicio Nacional de Turismo y los Servicios de Prensa y Propaganda diseñaron eficazmente una modalidad turística que se adecuaba y, a la vez, favorecía la cultura del gobierno nacional, definida, siguiendo a Juan Pablo Fusi, por las ideas fascistas de la Falange, el pensamiento social-conservador de la iglesia católica y los principios de orden, unidad nacional y autoridad de los militares, conjunto ideario que se prolongará hasta 1957-1961 (Fusi Aizpurúa, 1999; 2012).

El papel desarrollado por los intelectuales adscritos a la Falange fue determinante a la hora de construir una cultura de naturaleza fascista con fuerte componente propagandístico y justificativo del régimen en los años de guerra y primeros de postguerra, tanto por su responsabilidad política a cargo de organismos directivos como por ser los fundadores de significativas y casi únicas revistas de contenido cultural, vigentes tanto durante los tres años de la guerra civil como en los años de la década siguiente. La función pública la desempeñaron en los cargos que les asignó Ramón Serrano Súñez, Jefe Nacional de los Servicios de Prensa y Propaganda adscritos al Ministerio del Interior, a partir de 1938. Dionisio Ridruejo ocupa la jefatura del Servicio Nacional de Propaganda; José Antonio Giménez Arnau la de Prensa; Antonio Tovar la dirección de Radiodifusión del Estado; Pedro Laín Entralgo obtendrá la jefatura de Ediciones y el propio Serrano Súñez será el único jefe de Falange. Con estos cargos, los falangistas van a poseer cierto «control de la información y de la retórica del régimen» (Argaya, 2003: 26), que pondrán en práctica en sus proyectos culturales y sociales durante los primeros años del franquismo.

Entre las revistas fundadas por el grupo de intelectuales falangistas durante y después de la Guerra Civil, destacan Vértice. Revista Nacional de Falange Española Tradicionalista y de las JONS, que inicia su publicación en $1937^{3}$ y se mantiene hasta 1946, y Escorial. Revista de Cultura y Letras, que se edita durante el decenio 1940-1950. La revista ilustrada Vértice, considerada como la revista más importante del bando insurgente de la Guerra Civil, se orientó a la clase media de la España nacional y fue dirigida por Víctor de la Serna, Manuel Albar y José María Alfaro, acompañados por los jóvenes intelectuales falangistas Dionisio Ridruejo, Antonio Tovar, Rafael García Serrano, Gonzalo Torrente Ballester, Luis Rosales, Pedro Laín Entralgo y Luis Felipe Vivanco.

\footnotetext{
${ }^{3}$ El 19 de abril de 1937 se aprueba el Decreto de Unificación del nuevo régimen franquista, absorbiendo a la Falange y al Requeté, lo que permite encuadrar el movimiento nacional en un régimen jurídico de mando único y de partido único. De esta manera, el régimen franquista hace de la F.E.T. y de las J.O.N.S., «al menos teóricamente, su nervatura política e ideológica» (Argaya, 2003: 7).
} 
Los objetivos que persiguen este grupo de falangistas a través de su empresa editorial los recoge Ridruejo en la presentación, «A nuestros lectores», del ${ }^{\circ}$ 1 de Vértice, en el que señala: «con nosotros se presenta lo más florido de la intelectualidad española [....]. Así, los incrédulos verán dentro de nuestro territorio, y los malintencionados en el extranjero, como del lado de acá, en la España Azul, todavía existen valores capaces de realizar transcendentales misiones culturales. Vértice será un exponente tanto de valores morales como materiales [...]. Si Vértice pudiera llamar a nuestro camino a un solo incrédulo, o hiciéramos deponer su actitud a uno solo de nuestros enemigos, ya nos consideraríamos satisfechos». (Ridruejo, 1937: 10).

Terminada la contienda, los mismos intelectuales falangistas fundan en 1940 Escorial. Revista de Cultura y Letras, cuyo nombre rinde homenaje al mayor símbolo arquitectónico de la historia española y al que Dionisio Ridruejo dedicó un soneto en 1938, en cuyas seis últimas estrofas muestra el alto significado del Monasterio que le adjudica la historiografía española:

Ciudad de los siglos y las formas,

en desnudo paisaje con medida.

Cuerpo de razas que en tu mole informas.

Constancia y ambición, si grave erguida.

¡Oh templo de las sangres y las normas!

Cumbre de muertos en eterna vida

$$
\text { (Ridruejo, 1938). }
$$

La revista Escorial, en sus 10 años de, a veces, difícil andadura, fue dirigida sucesivamente por Dionisio Ridruejo, Pedro Laín Entralgo, José María Alfaro y Pedro Mourlane Michelena y tuvo como primeros Secretarios a Luis Rosales y a Antonio Marichalar, adscritos antes de su desaparición a las revistas culturales Cruz y Raya y Revista de Occidente, dirigidas por José Bergamín y por José Ortega y Gasset. Algunas de las últimas investigaciones y ensayos críticos, que profundizan en el significado de la revista Escorial y en la personalidad de sus responsables, subrayan la calidad intelectual del grupo falangista y el objetivo común que les une y persiguen, que no es otro que el de conseguir que la revista sea un proyecto cultural totalitario, «residencia y mirador de la intelectualidad española» (Juliá, 2002: 3) y, a su vez, el mejor instrumento de propaganda falangista para la cultura en el «Nuevo Estado» ${ }^{4}$.

\footnotetext{
${ }^{4}$ En la última década se han defendido algunas tesis doctorales sobre el significado cultural y alcance social de Escorial, entre las que destacan: Eduardo Ibáñez Pareja: Falangismo y propaganda cultural en el «nuevo estado»: la revista Escorial (1940-1950), Granada, 2008, consulta en: 
El Manifiesto Editorial del primer número de Escorial presenta a los lectores la tarea que anima a los intelectuales falangistas para llevar a cabo el nuevo proyecto editorial, que traspasa los contenidos estrictamente culturales y artísticos para poner el acento en el antipartidismo y en la integridad de los valores como consigna falangista. «El primer objetivo -el objetivo sumo-, señalan, de nuestra Revolución es rehacer la comunidad española, realizar la unidad de la patria y poner a esa unidad -de modo transcendente- al servicio de un destino universal y propio, afrontando y resolviendo para ello los problemas que, en orden al nombre, a la sociedad, al Estado y al Universo nos plantea el tiempo de nuestra historia más propia: el tiempo presente» (Escorial, 1940: 5). En este sentido, con la ayuda de la aportación de una pléyade de pensadores, escritores y artistas que están presentes en cada uno de los números bimensuales de más de 150 página, el mensaje o propaganda falangista adquiere una dimensión sobresaliente de la que con dificultad es apreciada en su totalidad por el resto de las élites franquistas. No obstante, desde el inicio, Escorial será concebida como una revista de propaganda, «en la alta manera», dicen, ya que «no hay propaganda mejor que la de las obras, y obras de España -propaganda de España- serán las del espíritu y la inteligencia para los que abrimos estas páginas» (Escorial, 1940: 5). En este sentido, el sumario de cada número se conforma, además de las obligadas referencias políticas, a los «hechos de la Falange», con apartados para el ensayo, la filología, la literatura, la poesía, el arte y la historia, los cuales casi siempre están referidos a los logros más excelsos acontecidos, casi siempre, antes del siglo XIX. Así ocupan un lugar destacado los trabajos referidos a los escritores del siglo de Oro, a monumentos arquitectónicos de época no posterior al barroco y a los lugares simbolizados por acontecimientos históricos o religiosos, que han tenido lugar en algún momento de su historia. Esta orientación temática, sobre la «España inmortal», fue seleccionada y sobreexplotada intencionadamente por otra cultura oficialista con pretensión más aleccionadora que educadora y por una propaganda turística también oficial con ambiciones culturales.

Uno de los más certeros diagnósticos sobre la cultura nacional-catolicista, que difunde y lleva a la práctica el nuevo régimen, es el que realiza Dionisio Ridruejo en 1972 titulado "La vida intelectual española en el primer decenio

Tesis doctorales en Red: http://www.tdx.cat/handle/10803/77974 (Consulta: 3/7/2014) y Joaquín Juan Peñalver, La revista Escorial: poesía y poética. Trascendencia literaria de una aventura cultural de la alta posguerra, Universitat de Alicante, consulta en Repositorio institucional de la universidad de Alicante, http://rua.ua.es/dspace/handle/10045/174/simple-search?query=juan +penalva (Consulta: 20/7/2014). 
de la postguerra" (Ridruejo, 1972), tanto más valioso cuanto que el autor era uno de los principales dirigentes de la Falange y jefe de propaganda a comienzos de los años cuarenta del siglo pasado. Entre otras cosas, Ridruejo dice que «durante casi toda la década (cuarenta) las notas características (de la vida intelectual española) serían estas: la investigación y la enseñanza se convierten en empresas oficiales de un Estado dogmático que con frecuencia los delega a una Iglesia de cruzada [...]. La especulación teórica-verse sobre temas metafísicos o sociológicos- se hace penosa por sus condicionamientos doctrinales y la presión de una censura de inspiración predominantemente eclesiástica [... ]. Las mismas limitaciones se daban para la literatura propiamente dicha, producida o importada. Nada que estuviera en el índice romano, por ejemplo, podía publicarse en España. Por lo que se refiere a los órganos de difusión, los que no eran oficiales estaban oficializados de hecho, como lo estaban las escuelas, los colegios y la Universidad, en los cuales la jerarquía eclesiástica tenía una potestad censoria» (Ridruejo, 1972: 71-72).

Así pues, el proyecto intelectual, fascista de contenido y liberal en la forma, de Escorial sobresalía en un régimen autoritario cuya cultura oficial era pobrísima a pesar de la creación del Ministerio de Educación Nacional en 1938 y del Consejo Superior de Investigaciones Científicas en 1939, este último en torno a un grupo de personalidades de la Asociación Católica Nacional de Propagandistas y del Opus Dei, encargados a través de la revista Arbor de historiar el pasado Nacional (Sevillano Calero, 1998).

Además, con ánimo de ofrecer hacia el exterior una imagen de calidad del país y del Régimen, que busca legitimarse en el exterior, sobre todo después de la Segunda Guerra Mundial, el gobierno recupera los Cursos de Verano para Extranjeros de las universidades de Jaca, Santander y Oviedo, que más tarde se ampliarán a otros lugares, y en 1945, por Decreto del 10 de noviembre crea la Universidad Internacional Menéndez Pelayo (UIMP), con lo que «la Dictadura se equipaba de un instrumento de enorme utilidad dentro de su estrategia de proyección cultural exterior» (Ferrer Cayón, 2011: 133)5. La UIMP se benefició de cierta apertura cultural del momento y de la presencia en ella de algunos de los falangistas históricos que alcanzaron, además, puestos relevantes

${ }^{5}$ La tesis de Jesús Ferrer Cayón: La instrumentalización política de la cultura durante el primer franquismo: La Universidad Internacional Menéndez Pelayo (UIMP) y el Festival Internacional de Santander (FIS), 1945.1957, leída en Santander, 2011, resulta imprescindible para conocer el proceso de consolidación de la UIMP y para entender el empeño y el esfuerzo que hizo el régimen franquista a la hora de utilizar la política cultural como estrategia para la legitimación internacional de la Dictadura. 
entre 1951 y 1956 como el nombramiento de Joaquín Ruiz Jiménez como Ministro de Educación Nacional, el de Joaquín Pérez Villanueva en la Dirección General de Enseñanza Universitaria y los de Pedro Laín Entralgo y Antonio Tovar como rectores de las Universidades de Madrid y Salamanca. Pero el intento de promover una cultura para el país de altas miras y más abierta y moderna que la del aparato educativo del Régimen en manos de la Iglesia y el Opus Dei se trunca en 1956, coincidiendo con los graves incidentes en torno a la contestación social ante los problemas económicos y con el movimiento universitario de oposición al régimen, que da por resultado el final de la política cultural aperturista de Ruiz Giménez y la desaparición un año después «del término Falange, sustituido por el mas inocuo de Movimiento Nacional y sus incontrolables propuestas revolucionarias en lo social y en lo económico» (Argaya, 2003: 83). No obstante, algunas de las ideas falangistas seguirán perdurando en los llamados falangistas legitimistas, que van a seguir manteniendo puestos relevantes en el Régimen hasta su disolución en 1977.

Pero van a ser las leyes de Reforma de la Segunda Enseñanza de 1938, la Ley de 20 de mayo de 1941 por la que se crea la Vicesecretaría de Educación Popular de FET y de las JONS, dependiente de la Secretaría General del Movimiento y que recoge las competencias de la Subsecretaría de Prensa y Propaganda, la Ley de Ordenación de la Universidad Española de 1943 y la Ley sobre Educación Primaria de 1945, dictadas por el Ministerio de Educación Nacional Española, las que van a permitir extender a toda la Nación la cultura y la enseñanza según los principios que subyacen en el espíritu del Movimiento Nacional y de la doctrina católica a través de la instauración en todos los niveles de las enseñanzas de las asignaturas de Religión, Formación Política y Educación Física. Incluso, años más tarde, con la sustitución del ministro de Educación, José Ibáñez Martín, por el falangista y aperturista Joaquín Ruiz Jiménez en 1951, en el examen de Preuniversitario, instaurado por la Ley de Ordenación de Enseñanza Media de 1953, en la parte de materias fundamentales y comunes, se dice que los ejercicios de comentarios de textos de literatura y del pensamiento versarán preferentemente sobre Religión, Formación del Espírito Nacional, Filosofía y Literatura (BOE, 27/2/1953).

Falange Española, con la divulgación de su doctrina y la «oficialización de sus rituales fascistas» (Fusi, 2012: 229), tuvo un papel esencial en la pretensión del Régimen de culturizar la sociedad española del momento, especialmente la juventud, hacia la que manifestó gran empeño. En este sentido, es revelador el mensaje didáctico contenido en el libro El Pueblo español y su destino. Ensayo y guiones para una enseñanza popular, escrito en 1952 por Antonio Almagro y editado por la editorial de la Delegación Nacional del Frente de 
Juventudes. El libro, inspirado en el pensamiento joseantoniano y falangista, pretende ofrecer «los rasgos concretos, configurativos de dicho modo de ser (el español) y de la definición de España como un destino en lo universal» (Almagro, 1952: 15). Destaca en el libro la habilidad, que aparece en la primera parte de la introducción teórico-filosófico, para identificar y diferenciar el concepto de "Hispanidad", que sería un tercer mundo cultural diferente a las formas de ser tradicionales de Oriente y Occidente, y la denuncia al constante empeño de nuestras minorías intelectuales de sumergirse y sumergirnos en lo europeo, «sin discriminar previamente si esta sumersión pudiera ser tóxica para nuestro íntimo modo de ser, para nuestro destino y para aquellos valores genuinamente hispánicos» (Almagro, 1952: 68)

La segunda parte del libro de Almagro muestra la forma y los contenidos de la enseñanza de la Historia Española, en el que destaca su enunciado de "España, pueblo decisivo en la historia de la humanidad" y su atención al estudio del "destino de la Hispanidad" en la Edad Antigua, Media y Moderna, «destino» que desaparece en el siglo xix y primer tercio del xx. Para la argumentación teórica, Almagro se inspira en las ideas de los intelectuales falangistas y, también, en el libro Portrait de l Espage, escrito por el hispanista francés Maurice Legendre en 1924 y traducido al español en $1955^{6}$, puesto que su interpretación trascendente de España y los españoles se adecuaba con la que quería transmitir el Régimen. El índice de la obra de Maurice Legendre es revelador de esta pretensión y se muestra bien a través de los títulos de los capítulos dedicados a "La tierra", "La raza", "El ingenio", "El carácter moral", "Los artistas", "Los héroes" y "Los Santos"; en "La tierra" destaca la Meseta Central, que es «la España esencial», y «Andalucía, elemento importantísimo, por su muy antigua civilización, de la persona España» (Legendre, 1955: 10-11).

La dimensión material, cultural y simbólica de los valores hispanos y su reconocimiento y difusión a través de diversas modalidades turísticas es tarea fundamental en la política del primer franquismo.

\section{MODALIDADES TURÍSTICAS Y PAISAJES EN LA POLÍTICA DEL PRIMER FRANQUISMO}

En plena guerra civil, el Servicio Nacional de Turismo y los Servicios de Prensa y Propaganda diseñaron una política cultural y turística acorde con los

${ }^{6} 1^{\text {a }}$ edición francesa: Maurice Legendre (1923): Portrait de l Espagne, Paris, Editions de la Revue des Jeunes, 2. edición española: Maurice Legendre (1955): Semblanza de España, Madrid, Ediciones y Publicaciones Españolas, S. A. Colección Hispanistas I. 
principios de un régimen totalitario de ideología nacional-catolicista con el objetivo de ayudar a destruir las estructuras de gobierno de la República e imponer las propias, que se consigue con el triunfo de la guerra por el bando sublevado en 1939 y que se prolongan en lo fundamental durante las dos décadas siguientes. Durante el primer franquismo, cultura, propaganda y turismo van a seguir conformando un todo, aunque los objetivos, ahora, serán «los de recuperar la unidad e identidad española, recatolizar España, convertir el Movimiento en partido único y, en política económica, instaurar la autarquía y cerrar las fronteras» (Fusi, 2012: 269). Y la política turística tendrá un importante papel en la consecución de estos objetivos.

En los apartados siguientes se analizan la tarea que lleva a cabo la Dirección General de Turismo, dependiente del Ministerio de Gobernación, de 1939 a 1951, el sentido de los primeros cambios técnicos, que no ideológicos, del Ministerio de Información y Turismo y el papel innovador de la Falange que va a promocionar un cierto tipo de turismo de interior y de costa a través de una serie de actividades vinculadas con el ocio y el descanso de los españoles, poniendo en práctica, de esta manera, la dimensión social de su pensamiento.

\section{El paisaje en los itinerarios y rutas turísticas de la Dirección General de Turismo}

La Dirección General de Turismo (DGT), dependiente del Ministerio de Gobernación, como ya se ha comentado, es el principal responsable público en materia turística de 1939 a 1951 y hereda las competencias que había tenido el Servicio Nacional de Turismo durante los dos años anteriores en la España sublevada; también hereda las prácticas turísticas que el Servicio había diseñado durante la contienda, las conocidas como Rutas de Guerra, así como a su máximo responsable, Luis Antonio Bolín y, por último, también hereda la carga ideológica que se le adjudica al turismo, ahora utilizado como instrumento importante para reforzar la unidad e identidad nacional.

Una de las primeras tareas de la DGT fue el diseño del marco institucional necesario para llevar a cabo la práctica turística en un país lleno de dificultades técnicas y carente de bienes y servicios de primera necesidad y, además, con la pretensión de que el turismo tuviera un alcance nacional y que la mayor parte de lugares y regiones españolas pudieran ser susceptibles de ser visitados. Algunos de los autores, que se han señalado al comienzo del texto, dan sobrada cuenta de la normativa que se aprueba en los primeros años de la década de los cuarenta del siglo xx para regular el turismo y de la estructura y actividades de 
la DGT (Correyero, 2004; Pellejero, 2004). El conjunto legislativo de alcance nacional intenta crear y regular aspectos relacionados con la práctica turística como el alojamiento, la publicidad, los transportes, el crédito hotelero, el sindicato de hostelería y la regulación sobre la entrada de extranjeros. Por otro lado, la estructura de la DGT la conformaba las secciones de Asuntos Generales, Propaganda y Publicaciones; Deportes; Alojamientos; Transportes y Comunicaciones; Información; Contabilidad y el Departamento de Rutas Nacionales. De todos ellos, Propaganda y Publicaciones y el Departamento de Rutas Naciones son las Secciones que se vinculan muy directamente con aspectos del territorio y el paisaje, en tanto que el Departamento de Rutas Nacionales tiene competencias para diseñar, promocionar y vender determinados itinerarios turísticos por el territorio nacional y la sección de Propaganda y Publicaciones, a través de la edición y distribución de folletos y publicaciones turísticas, tiene capacidad para promocionar sitios y lugares que, situados en los itinerarios de las Rutas Nacionales, gozan de recursos turísticos que se avienen con los valores territoriales que la ideología franquista quiere ensalzar.

El Departamento de Rutas Naciones aplica para todo el territorio nacional el diseño de itinerarios turísticos que ya se había ensayado con las Rutas de Guerra durante los dos últimos años de la Guerra Civil en el territorio nacional que se iba conquistando. Mientras que en 1938 y 1939 el Servicio Nacional del Turismo plantea dos recorridos turísticos, uno por el norte peninsular y otro por Andalucía para visitar los paisajes de la España pacificada y los lugares que son símbolos de resistencia a la República, la DGT diseña en estos años las excursiones organizadas por el departamento de Rutas Nacionales, también denominadas itinerarios por las carreteras de España y circuitos en autocar por España. De las Rutas, se da cuenta en los dos principales medios de comunicación y promoción oficial vigentes en estos años: El Boletín de Información de la Dirección General del Turismo ${ }^{7}$ y las series temáticas de folletos y mapas turísticos editados por la Sección de Propaganda y Publicaciones de la Dirección General del Turismo y sus delegaciones provinciales ${ }^{8}$. Los 25 núme-

${ }^{7}$ Del Boletín de Información de la Dirección General del Turismo se publicaron 25 números, de 1947 a 1952, por lo tanto, abarca el tiempo que va desde el final de la Segunda Guerra Mundial al siguiente año de la creación del Ministerio de Información y Turismo. El Boletín se remite gratuitamente a las Agencias de Viaje y entidades relacionadas con el turismo y a cuantas personas lo solicitan por escrito.

${ }^{8}$ Los folletos y mapas de información turística utilizados en este trabajo se han consultado en los Fondos Documentales de la Secretaría de Estado de Turismo del Ministerio de Industria, Energía y Turismo y en los fondos de la Biblioteca Nacional, Sala Goya. 
ros del Boletín, publicados entre 1947 y 1952, recogen la información principal en materia turística que también se reutilizará en otros formatos de comunicación oficial. Además de informar sobre las Rutas, el Boletín también lo hace de otros muchos aspectos relacionados con la práctica turística, cuyos textos son, a su vez, un buen ejemplo de la retórica propagandística y de la selección de imágenes, que se incorporan con cierta profusión para justificar esta actividad, y de lugares y paisajes que la población nacional y extranjera pueden visitar.

De lo que informa el Boletín destaca, por su dimensión territorial, todo lo concerniente a las Rutas Turísticas diseñadas por la DGT como son los días que se emplean en cada viaje, los $\mathrm{Km}$. que se recorren, los lugares y ciudades que se visitan, el hospedaje que se utiliza y esquemas sumamente elementales de cada recorrido propuesto (figura 1).

FIGURA 1

ESQUEMA DEL ITINERARIO DE DOS RUTAS DE ESPAÑA, CON MADRID Y BARCELONA COMO PUNTOS DE ORIGEN Y DESTINO

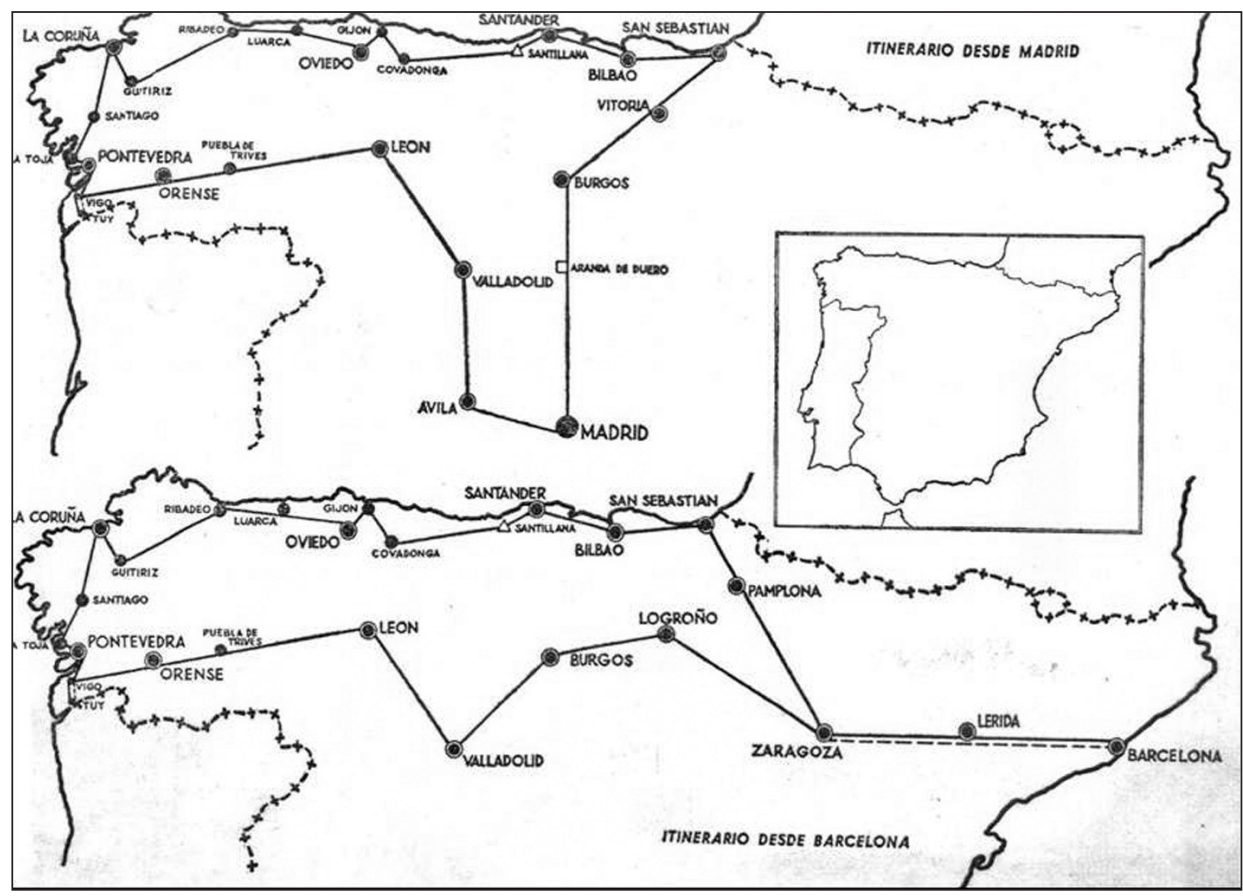

Fuente: "Circuitos en Autocar por España”, Boletín de la Dirección General del Turismo, 21, 1951.

Estudios Geográficos, Vol. LXXVII, 281, pp. 443-467, julio-diciembre 2016 ISSN: 0014-1496, eISSN: 1988-8546, doi: 10.3989/estgeogr.201614 
La figura 1 reproduce los esquemas de los itinerarios 1, "Ruta Norte-Noroeste de España" de $2.212 \mathrm{Km}$, y 2, "Ruta Norte de España" de $2.718 \mathrm{Km}$., de los 10 "Circuitos en autocar por España", tal y como aparecen recogidos en $e l$ Boletín y en el folleto de la DGT titulado Rutas de España, servidas por la Empresa de Autotransportes Turísticos por Carretera (ATESA) ${ }^{9}$. A las dos Rutas señaladas, se suman las de Aragón-Levante (1.399 Km.), Galicia-Castilla-Andalucía (2.052 Km.), Algeciras-Behobia por Madrid (1.293 Km.), Costa del Sol (1.802 Km.), Castilla la Vieja y León (947 Km.), Madrid-Andalucía-Marruecos $(2.419 \mathrm{Km})$, Madrid-Ávila-Salamanca-Extremadura $(873 \mathrm{Km})$ y las 9 excursiones desde Madrid $(1.400 \mathrm{Km})^{10}$. Los 10 recorridos suman un total de 17.115 $\mathrm{Km}$. y unen en cada uno de ellos entre 10 y 19 ciudades, la mayoría son capitales de provincia y otras, que no lo son, cuentan con Paradores Nacionales, como Mérida, Oropesa, Úbeda o El Paular o Albergues de Carretera, como Medinaceli, Aranda de Duero, Manzanares, Quintanar de la Orden o Benicarló. El proyecto turístico de las Rutas tiene alcance nacional y, a través de la disponibilidad de la red de carreteras del país, la DGT quiere que todas las regiones españolas puedan ser visitadas, como también tiene alcance nacional, y relacionado con el trazado de las Rutas, el proyecto heredado y ampliado por la DGT de la red de Paradores Nacionales y Albergues de Carretera. Los primeros están vinculados con la recuperación de edificios históricos relevantes para un hospedaje de calidad y los segundos surgen para suministrar hospedaje a recorridos turísticos poco dotados de este tipo de equipamiento turístico ${ }^{11}$.

Junto con el proyecto de las Rutas Nacionales, la DGT oferta también itinerarios turísticos temáticos como la Ruta de Don Quijote, cuya información aparece en el Boletín junto con una fotografía del paisaje inmenso, austero y recio de La Mancha que recorrió Don Quijote bajo el ensueño de su sublime locura, o la Ruta de las Catedrales, en la que se visita las ocho ciudades castellano-leo-

${ }^{9}$ ATESA «ofrece a cuantos visiten España autocares [...] para recorrer el país por distintos circuitos fijos en viajes a "forfait" [...] organizados con la colaboración de Agencias de Viajes establecidas en España, las cuales se encargan de reservar habitaciones y comidas a lo largo de la ruta, de las visitas a monumentos y lugares de interés» (Boletín de la Dirección General del Turismo, 21, 1951, p. 20).

${ }^{10}$ Las 9 excursiones desde Madrid son las siguientes: Madrid-El Paular (por Lozoyuela) Madrid-El Paular (por Colmenar Viejo); Madrid-Alcalá; Madrid-La Granja-Segovia: Madrid-Escorial-Ávila; Ávila-Gredos-Oropesa-Madrid; Madrid-Illescas-Toledo; Madrid-Aranjuez y Madrid-Cuenca.

${ }^{11}$ La DGT tiene interés en publicitar los Paradores Nacionales, los Albergues de Carretera, los Refugios y las Hosterías y edita folletos al caso en varios idiomas con textos de referencia, fotografías y mapa de localización. 
nesas que cuentan con este rico patrimonio histórico-artístico. También, la DGT, a través del departamento de Rutas Nacionales, organiza otras excursiones en relación con las fiestas de Semana Santa en Andalucía o las excursiones radiales de verano desde San Sebastián, Santander y Barcelona; también diseña hipotéticos "itinerarios turísticos climatológicos", donde la visita a cada lugar viene recomendada en su mejor momento climatológico del año. Incluso se publicitan lugares de veraneo como los sitios de altura en las provincias de Ávila, Segovia y Soria. Así pues, los reclamos que utiliza la DGT para la promoción turística del país se centran en la belleza de elementos de su patrimonio natural, histórico, etnográfico, artístico y arquitectónico y casi siempre acompañados de habituales descripciones banales y estereotipadas.

Otra cuestión que está muy presente en los textos propagandísticos dirigidos a los turistas nacionales y extranjeros es la de resaltar como una gran cualidad la variedad regional de España. En el folleto a color publicado por la DGT y dirigido a los turistas españoles y extranjeros, titulado Spain welcomes visitors, se presenta a España como el país donde «la vida sonríe a la luz de un sol perenne» y donde «conviven el encanto de oriente y el confort de occidente». Además, no «hay nada mejor para aprender a conocer a España que contemplar el espectáculo de su Historia, cuyo fiel reflejo es el arte hispánico», pero, sobre todo, sobresale en España, «su diversidad, característica que se refleja, como en el paisaje, en costumbres, fiestas, trajes típicos, danzas, canciones e industrias artesanas que, por su originalidad y belleza, constituyen en cada región logrados atractivos» (Dirección General del Turismo, 1938-1951) ${ }^{12}$. El folleto se completa con fotos de monumentos, de paisajes de playa y de montaña, de calles y plazas españolas muy conocidas y de personajes con atuendo regional, distribuidas entre el Norte, el Centro, el Este y el Sur del país.

Tanto el tono de los textos como el tipo de fotografías que aparecen en el folleto Spain welcomes visitors están inspirados en la obra germinal de 1943, Apología Turística de España. Cuatrocientas treinta y nueve fotografías de Paisajes, Monumentos y Aspectos típicos españoles, con texto, selección de fotografías y dirección artística de la edición de Rafael Calleja, Jefe de Propaganda y de Publicaciones de la Dirección General de Turismo. El discurso de defensa del turismo español en la Apología se extiende a toda la Nación, porque toda ella y, a la vez, cada una de sus regiones son dignas de ser visitadas. La obra de Calleja incide en el gran atractivo que se deriva de la variedad geográfica del país: «Lo

12 La mayoría de folletos de la DGT no tienen fecha de edición, por lo que en la referencia bibliográfica de los fondos de la Biblioteca Nacional, la fecha de edición se sustituye por el periodo de vigencia del organismo editor. 
mejor de España (dice) es la frecuencia y la diversidad de motivos que de Norte a Sur, de Levante a Occidente, se encuentran para sentir orgullo de ser español. Rica, varia, multiforme España" (Calleja, 1943: 45). El interés por la obra de Rafael Calleja va a continuar en el tiempo y será reeditada 13 años después, en 1957, ahora con el título de Nueva Apología Turística de España (Calleja, 1957).

Junto a los textos e imágenes de propaganda turística emitidos por el Régimen, destaca la obra del geógrafo hispanista francés Jean Sermet que, además de tener una abundante bibliografía sobre la geografía regional española, escribió una guía turística de España titulada Image de l'Espagne, donde toman protagonismo las 150 fotografías distribuidas entre los cuatro grandes territorios españoles que la mayoría de autores del momento diferencian: l'Espagne $d u$ Nord; l'Espagne central, l'Andalousie y l'Espagne de l'Est. (Sermet, 1954). De estas 150 fotografías que ilustran la Image de l’Espagne, más de 50 están realizadas por el propio Jean Sermet, sobre todo las que descubren para los españoles y extranjeros lugares, monumentos y paisajes, que son menos conocidos del Pirineo, de Castilla-León, de la Sierra de Guadarrama y de Andalucía. La obra de Sermet es representativa de una forma de entender y dar a conocer el paisaje español orientado al turismo nacional y extranjero diferente a la imagen oficial creada y proyectada por los organismos turísticos del primer franquismo.

\section{Lugares y paisajes en el turismo social de la Falange}

Además de la modalidad estrictamente turística de las rutas y excursiones de la Dirección General del Turismo, vinculada con la red nacional de paradores y albergues nacionales y orientada para viajeros nacionales y extranjeros, en la década de los años cuarenta del siglo xx surge un conjunto de actividades relacionadas con el ocio y el descanso de los españoles, que vendría a coincidir con lo que actualmente se conoce como turismo social. La responsabilidad política de este tipo de turismo recayó en la Falange, ya que «esta actividad se adecuaba con su ideología nacionalsindicalista y su programa de justicia social» (Argaña Roca, 2003: 17). En este sentido, el régimen encomendó a la Falange dirigir las secciones de los Sindicatos de trabajadores ${ }^{13}$, el

13 Desde el inicio de la nuevo Régimen, Falange asume toda la actividad sindical que concentra en su Organización Sindical, regulada por la Ley de la Unidad Sindical (BOE, 26-11949). Un año después se aprueba la Ley del Sindicato Nacional de Hostelería (BOE, 23-VI-1941), por la que se regula una parte sustancial de las actividades turísticas. 
Sindicato de Estudiantes Universitarios (SEU), la Sección Femenina y la Organización Juvenil Frente de Juventudes, y en ellas La Falange puso en práctica la función educadora y de mejora social hacia trabajadores, estudiantes, mujeres y jóvenes. Sobresale de esta práctica la ejercida en el Frente de Juventudes, que permitió extender a toda la juventud española la cultura, la educación, la información y las actividades en el tiempo libre siguiendo los principios del Movimiento Nacional ${ }^{14}$. En este sentido, la Falange a través del Frente de Juventudes llevó a cabo un determinado turismo vacacional de alcance nacional, esencialmente deportivo, a través del establecimiento de la Red Nacional de Campamentos. Según un documento realizado por la Dirección Nacional de la Juventud, en 1946 había en España 83 campamentos, distribuidos por todas las regiones españolas, clasificados según el tipo de emplazamiento. Así, había 23 campamentos «de playa», 39 eran «de montaña», con más de 800 metros de altura, y 31 se localizaban en el «interior». Los 83 campamentos nacionales ofrecían a mediados de los años cuarenta del siglo pasado 19.773 plazas. A cada campamento se le asignaba un nombre representativo del régimen, como nombres de sitios religiosos, de personajes y de hazañas gloriosas de España. Están los de Francisco Franco, José Antonio, Virgen de Loreto, Viriato, Rey Pelayo, Jaime I o Montezurra. Cada Delegación Provincial de la Juventud diseña una ficha por campamento donde se indican cuestiones relacionadas con el emplazamiento, con los valores del paisaje natural, equipamientos y actividades (Delegación Nacional de la Juventud, 1946)

El proyecto de formación y de ocio del Frente de Juventudes, a través de la Red Nacional de Campamentos, fue desvirtuándose en sus contenidos más ideológicos durante la década siguiente hasta pasar a llamarse Organización Juvenil Española; si bien, la red de campamentos se mantuvo en las décadas siguientes como oferta social de deporte y ocio para la juventud española.

La Falange también extendió su labor cultural y social a los trabajadores españoles a través de la Obra Sindical "Educación y Descanso", que surge en 1940 como heredera de la Obra Nacional "Alegría y Descanso", creada en 1939 a imagen de las instituciones italianas y alemanas, Dopolavoro y Fuerza por la Alegría. Estas instituciones aparecen en la década de los años treinta del siglo xx y tienen como objetivo «el control del ocio obrero» (López Gallegos, 2004: 144). Si bien, para la versión oficial española, el fin de la Obra Sindical

14 El Frente de Juventudes de instituye por Ley de 6 de diciembre de 1940 (BOE, 07/12/1940) y permanece como tal hasta 1955. El Delegado Nacional durante esta etapa fue José Antonio Elola Elaso. 
era el de prestar «atención a la formación humana del trabajador, tanto en su aspecto cultural como en el físico» (Corral, 1967: 7), ya que, como se dice en el Catálogo de la $1^{a}$ Exposición Nacional de Arte, celebrada en 1941, «hasta ahora, el Estado olvidó a esa masa esforzada, creadora de riqueza, constituida por los productores españoles [...]. Pero hoy, en la España nacional-sindicalista, Educación y Descanso recoge a estos hombres, los conduce hacia el Arte, no solo en pasiva contemplación, sino en ambiente y fervorosa práctica, y da a conocer con la debida solemnidad unas obras en cuya realización pusieron todo su fervor y desinterés» (Obra Sindical "Educación y Descanso", 1941: 5). Los medios que utilizó "Educación y Descanso" para conseguir sus fines fueron las Agrupaciones Artísticas de danzas, coros, rondallas, teatro, cine; los cursos de orientación artística, exposiciones de obras realizadas y visitas a museos; los cines-club, charlas y conferencias y visitas por la ciudad que los llama «itinerarios artísticos y excursiones» (López Gallegos, 2004: 145). Toda esta actividad tiene lugar en el marco responsable de la colaboración entre patronos y obreros «a los que había que premiar o atraer a través de propuestas destinadas al ocio y la cultura» (Ferraz Lorenzo, 1997: 219), tal y como se señala en el Fuero del Trabajo de $1938^{15}$.

La Organización Sindical "Educación y Descanso" contó con un departamento de Viajes y Excursiones, del que dependía la sección de Ciudades Sindicales y Residencias y Albergues. Las Ciudades y la red de Residencias Sindicales van a ser modalidades de alojamiento turístico de ámbito nacional, donde se combina el ocio ordenado y la culturización falangista, inculcadora de ideas, valores y comportamientos «de hondo calado atávico y tradicionalista» (Ferrán Lorenzo, 1997: 224). De los primeros años del franquismo destacan las Ciudades Residenciales o de vacaciones de Marbella, Perlora (Asturias) y Tarragona y un número de Residencias que fue aumentando a lo largo de los años cuarenta del siglo xx. En 1941, había 12 Residencias y en 1948 la Red de Residencias y Albergues ya contaba con 28 establecimientos, puesto que todas las provincias españolas, a través de las Delegaciones provinciales, comarcales y locales podían contar con este tipo de turismo residencial vacacional. Las Ciudades Residenciales se localizaron en lugares dotados de vías de comunicación y cercanos a la costa o la playa, como, por ejemplo, la

15 En el Apartado segundo del Artículo quinto del Fuero del Trabajo se señala que «todo trabajador tendrá derecho a unas vacaciones anuales retribuidas para proporcionarle un merecido reposo, organizándose al efecto las instituciones que aseguren el mejor cumplimiento de esta disposición», (Ferrán Lorenzo, 1997: 220). 
FIGURA 2

CARTEL TURÍSTICO DE LA OBRA SINDICAL "EDUCACIÓN Y DESCANSO"

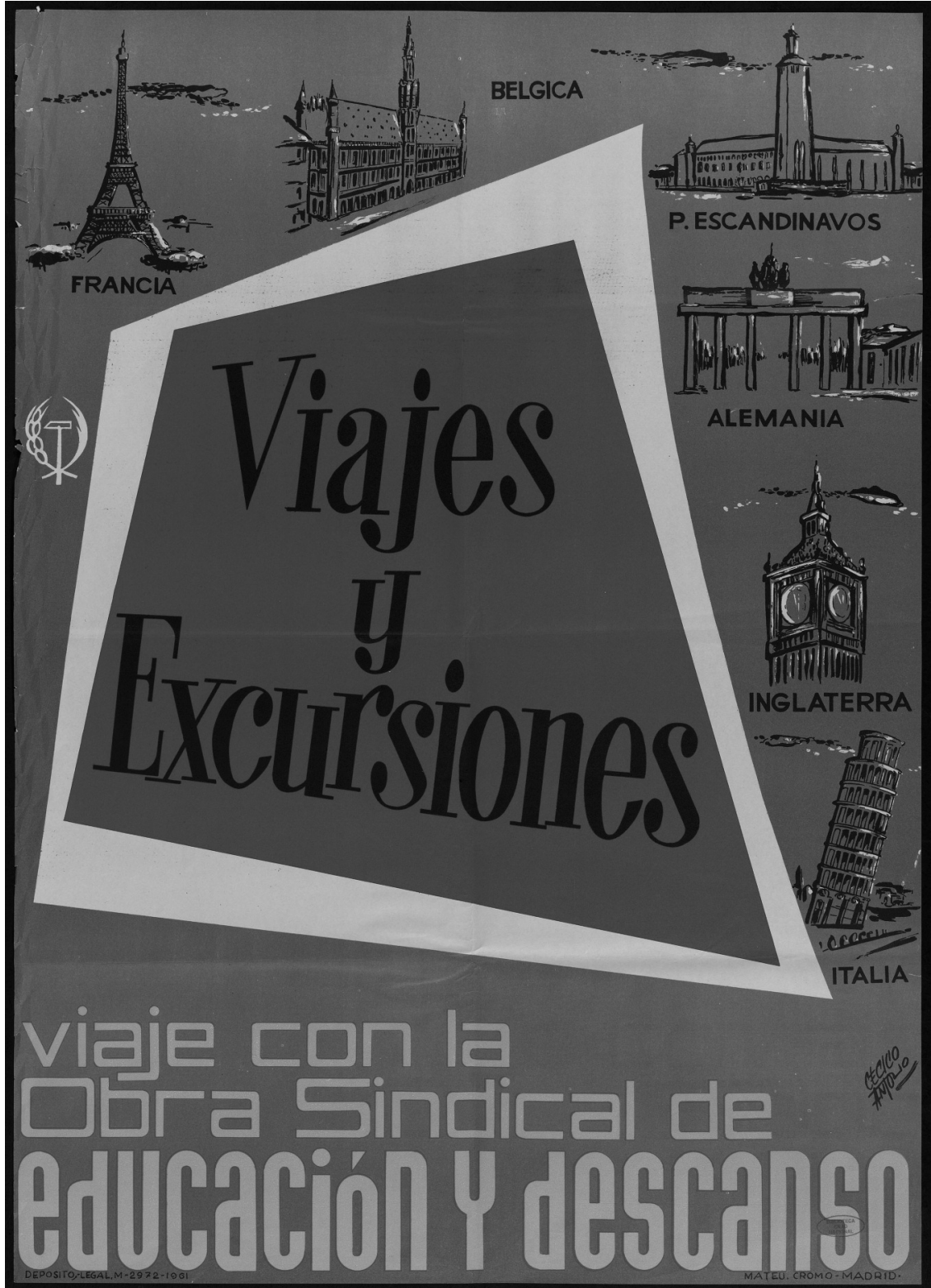

Fuente: Obra Sindical “Educación y Descanso”, (Biblioteca Nacional. Sala Goya, AHC/5780).

Estudios Geográficos, Vol. LXXVII, 281, pp. 443-467, julio-diciembre 2016 ISSN: 0014-1496, eISSN: 1988-8546, doi: 10.3989/estgeogr.201614 
ciudad de Perlora que se localizó en el concejo de Carreño, a $36 \mathrm{Km}$. de Oviedo y a $12 \mathrm{Km}$. de Gijón, sobre la superficie plana de la rasa litoral asturiana; ocupaba $35 \mathrm{Ha}$ y contaba con un edificio residencial colectivo y unos 100 chalets individuales (Sanz Díaz, 2000). Las Residencias, establecimientos numerosos y versátiles, se localizaron en zonas de interior y de playa y podían ser masculinas, femeninas, familiares y, también, de primavera, verano o para todo el año, se establecían turnos para su uso y las prácticas turísticas se limitaban a usar el lugar y a realizar excursiones por sus alrededores.

Como ocurre con los Campamentos del Frente de Juventudes, que van a continuar en el tiempo, también las Ciudades y las Residencias mantuvieron su función de hospedaje para un turismo fundamentalmente nacional y la Obra Sindical "Educación y Descanso" pudo embarcarse en la década siguiente como promotor de un turismo exterior en crecimiento, salvadas ya las principales barreras políticas y económicas. El cartel de la figura 2, donde "Educación y Descaso" promociona viajes y excursiones a Francia, Bélgica, Países Escandinavos, Alemania, Inglaterra e Italia, testimonia el compromiso de la Obra Sindical en la apertura política y turística del Régimen hacia los principales países europeos.

\section{Territorio y paisajes en el primer Plan Nacional de Turismo}

El primer Plan Nacional de Turismo (Ministerio de Información y Turismo, 1953), con su edición numerada para estudio y corrección, se publica en 1953, justo un año después de la reorganización del Ministerio de Información y Turismo, surgido del Decreto-Ley del Gobierno de 19 de julio de 1951. El nuevo Ministerio se concibe como una novedad institucional para una nueva situación -al menos teórica- de la política turística, ya que la Dirección General de Turismo seguirá teniendo parecidas competencias en materia de inspección, fomento y propaganda de las actividades turísticas, aunque su antiguo director, Luis Antonio Bolín, sea sustituido por Mariano Urzaiz. Comienza así una etapa, que se pretende diferente, para la ordenación del turismo a nivel nacional ${ }^{16}$. La oportunidad en el momento de la redacción del

${ }^{16}$ Bajo el mandato de Mariano Urzaiz, se regula la actividad de guías, intérpretes y correos de turismo; se promulga la Ley para ampliar la red de Albergues y Paradores de Turismo y se instituye un premio a la mejor tesis dedicada al estudio de los problemas que afectan al movimiento turístico, en relación con el interés nacional. y se regula la denominación e instalación de Paradores y Albergues de Turismo (Pérez Guerra y Ceballos Martín, 2001). 
Plan Nacional de Turismo viene dada también por el incremento del turismo que se está produciendo desde finales de la década de los cuarenta y su repercusión creciente en la creación de riqueza para la Nación, tal y como lo muestran los datos en recientes publicaciones. Si en 1940, en España entraron 20.000 turistas, que aportaron un $0,1 \%$ al PIB nacional, en 1950 visitaron el país 460.000 turistas, lo que representó un 0,4\% de la riqueza nacional creada en ese año y en 1955 ya hubo 1.380 .000 turistas, lo que aportó al PIB nacional un 1,36\% (Vallejo Pousada, 2014: 27). En este contexto, parece lógico pensar que la búsqueda de objetivos económicos a través del turismo es ahora igual de importante, o incluso se impone como va a ocurrir en las etapas posteriores, a la obtención de rendimientos estrictamente políticos o ideológicos como ocurrió en los años previos.

El tono del texto del documento y los aspectos relacionados con el turismo que el Plan plantea recuerda, en gran medida, el tono y los temas de interés que definía y caracterizaba la política turística de la década anterior. La orientación de un turismo nacionalista se mantiene, los prejuicios hacia el mal conocimiento de los turistas de la España del momento continúan y no hay innovación en los soportes técnicos de la actividad turística; la única novedad se refiere a la introducción de una cierta estrategia turística de carácter territorial a través de la definición y delimitación de Zonas de Interés Turístico, que van a ser consideradas como un nuevo instrumento para promover, ordenar y mejorar el territorio nacional para el turismo, ya que se invita a todas las provincias a que participen en la delimitación y promoción de Zonas de Interés Turístico en sus territorios.

El carácter de continuidad del Plan se muestra en los considerados como beneficios del turismo hacia el país, en donde «el primero y principal es el conocimiento directo de una realidad desfigurada por la propaganda tendenciosa» (Ministerio de Información y Turismo, 1953: 11); también se aprecia la continuidad en la justificación de la mejora, ampliación y localización de la Red de Paradores Nacionales y Albergues de Carretera, que responden a que «existen grandes zonas de territorio nacional desprovistas de este género de alojamientos» y que los «motivos de carácter religioso, histórico, artístico o simplemente pintoresco aconsejan la construcción de otros alojamientos del mismo tipo en las proximidades de Ribadeo, Santiago de Compostela, Villafranca del Bierzo, Tordesillas, Guadalupe, Arruzafe, Jerez de la Frontera, proximidades de Estepona, costa de Granada y en las proximidades de Benidorm» (Ministerio de Información y Turismo, 1953: 47). De ahí que llame la atención la pretendida modernidad del enfoque territorial del Plan con la delimitación y caracterización de futuras Zonas de Interés Turístico. 
Como ejemplo metodológico para la delimitación y caracterización de esas futuras Zonas por el territorio nacional, el Plan incorpora dos ejemplos, la Zona Turística de la Costa del Sol y la Zona Turística de la Costa Brava. En ambos territorios españoles, el peso turístico es ya relevante a principios de la década de 1950 y su impacto económico, social y territorial lo es de igual modo. De ahí, que no sea extraño que el Plan aproveche estos territorios y paisajes de costa para llevar a cabo una propuesta para su ordenación y elevarla a otras partes del país.

Según el diagnóstico que el Plan hace de la Zona Turística de la Costa Brava, ésta está compuesta de 45 municipios y comprende la parte del litoral, desde Ampurias a Blanes. Estos municipios están salpicados de torres, villas y casas de recreo levantadas por la iniciativa privada, pero toda la zona adolece de vías de comunicación adecuadas, cuestión que debe resolverse. La Zona Turística de la Costa del Sol comprende el territorio que suman los 21 municipios litorales, desde Motril a Algeciras, cuya población conjunta ha crecido entre 1940 y 1950 en un 22\%, mientra que la población del país lo ha hecho durante esta década en apenas un $8 \%$. Dentro de la Costa del Sol comienzan a diferenciarse por sus tasas de crecimiento demográfico los municipios de Algeciras-La Línea y Málaga-Torremolinos. Este crecimiento diferencial se explicaría por el impacto a principios de 1950 del turismo de costa, en crecimiento, frente al estancamiento del turismo de interior a pesar de los esfuerzos de la política turística puesta en práctica durante el primer franquismo.

\section{DisCUSIÓN}

El estudio confirma algunos hechos resaltados por la historiografía del turismo y sus relaciones con la cultura en los años del primer franquismo. En primer lugar, aparece la justificación del tiempo que corresponde al primer franquismo y aquí utilizado, de 1939 a 1956. Esta delimitación temporal resulta de implicaciones de fondo, como dice Elías Díaz, de carácter cultural, ético y político, que se dan en estos años, más que de implicaciones estrictamente económicas (Díaz, 2000). En segundo lugar, e intentando huir de la segmentación radical de los hechos en tiempos definidos, en el trabajo se reconocen las conexiones, que son muchas veces continuaciones, de la cultura y el turismo del primer franquismo con la cultura y el turismo ensayados por el bando sublevado en la España Nacional durante la Guerra Civil Española; también, algunas prácticas turísticas, que surgen en estos años, se prolongan hasta el final de la Dictadura. En tercer lugar, el estudio corrobora la influen- 
cia de la cultura falangista, soporte teórico del Régimen, en la presentación y justificación del turismo en sus diversas manifestaciones.

Con respecto a la consideración del paisaje en la política turística del primer franquismo -cuestión mucho menos tratada en la bibliografía españolalo que el trabajo muestra es que el entendimiento moderno del paisaje está ausente en el discurso y en la práctica oficial del turismo de todo el periodo analizado. Las alusiones, observaciones y descripciones del paisaje español, por donde se diseñan las rutas e itinerarios turísticos y excursiones, ofrecen una imagen estereotipada y banal del territorio que se recorre y se visita, sembrada de alusiones nacionalistas, religiosas, históricas y costumbristas. A pesar de resaltar la variedad de las regiones españolas y considerar esta cualidad como un valor hispano, no se utilizan para justificar esta diferencia elementos naturales, patrimoniales y simbólicos genuinos de cada territorio sino que, por el contrario, se hacen comunes los elementos de referencia que están presenten en todos ellos. Se alude así a los paisajes naturales cuando sobresalen por la grandiosidad de sus pendientes, cimas o bosques situados en cualquier región española, a cualquier lugar con historia por contener hechos heroicos dignos de ser recordados y lo mismo pasa con los paisajes patrimoniales con valores arquitectónicos. Esta generalización en la valoración de los lugares y los paisajes es resultado de la homogeneización cultural y política que impone el nuevo Régimen a todo el país.

No obstante, las diferentes modalidades turísticas gestionadas por el Régimen en estos años promovieron a nivel nacional para los españoles y más adelante también para los turistas extranjeros los viajes, las excursiones, los deportes de caza y pesca, los deportes al aire libre y las vacaciones en sitios diferentes al de la residencia habitual, hecho que permitió dar a conocer y promocionar partes importantes del territorio nacional y dio lugar así a una etapa inicial del turismo contemporáneo español que se caracteriza por su tardía diversificación en su modalidad y destinos.

\section{BIBLIOGRAFÍA}

Almagro, A. (1952): El pueblo español y su destino: ensayo y guiones para una enseñanza popular, Madrid, Delegación Nacional del Frente de Juventudes.

Argaya Roca, M. (2003): Historia de los falangistas en el franquismo, 19 de abril de 1937-1 de abril de 1977, Madrid, Plataforma.

Bayón Mariné, F. (coord.) (1999): 50 años de turismo español: Un análisis histórico y estructural, Madrid, Editorial Centro de Estudios Ramón Areces, primera edición digital de 2009: ISBN eBook 978-84-8594-288-6. 
Brandis, D. y Río, I. del (2016): “Turismo y paisaje durante la Guerra Civil Española: 1936-1939", Scripta Nova, XX/530 (15 de febrero de 2016).

Cal, B, y Correyero, B. (2008): Turismo: la mayor propaganda de Estado. España: desde los orígenes a 1951, Madrid, Visión Net.

Calleja, R. (1943): Apología Turística de España. Cuatrocientas treinta y nueve fotografías de Paisajes, Monumentos y Aspectos típicos españoles, Madrid, Publicaciones de la Dirección General del Turismo.

Calleja, R. (1957): Nueva Apología Turística de España. Cuatrocientas treinta y nueve fotografías de Paisajes, Monumentos y Aspectos típicos españoles, Madrid, Publicaciones de la Dirección General del Turismo.

Corral, J. del (1967): Labor cultural de la Obra Sindical Educación y Descanso, Madrid, Ferreira, S. A.

Correyero Ruiz, B. (2003): "La propaganda turística española en los años del aislamiento internacional", Historia y Comunicación Social, 8, pp. 47-61.

Correyero Ruiz, B. (2004): "La administración turística española entre 1936 y 195: El turismo al servicio de la propaganda política", Estudios Turísticos, 163-164, pp. 55-79.

Delegación Nacional de la Juventud (1946): Red Nacional de Campamentos, Madrid, Secretaría General del Movimiento.

Díaz, E. (2000): "Los inicios de la reconstrucción de la razón, 1939-1956”, en AA. VV., Dos décadas de cultura artística en el franquismo (1936-1956), Granada, Universidad de Granada, pp. 15-29.

Dirección General del Turismo (1938-1951): Spain welcome visitors, folleto plegable de la Dirección General del Turismo.

Ferraz Lorenzo, M. (1997): "Reglamentación, constitución y desarrollo de la Obra Sindical Falangista 'Educación y Descanso'. Especial referencia al caso tinerfeño", Anuario del Archivo Histórico Insular de Fuerteventura, 10, pp. 217-238.

Ferrer Cayón, J. (2012): La instrumentalización política de la cultura durante el primer franquismo: la Universidad Internacional Menéndez Pelayo (UIMP) y el Festival Internacional de Santander (FIS), 1945-1957, Santander, Universidad de Cantabria, en línea, http://hdl.handle.net/10803/80772 (Fecha de consulta: 4/5/1014).

Fusi Aizpúrua, J. P. (1999): "La cultura del antifascismo", en Capa: Cara a cara. Fotografías de Robert Capa sobre la Guerra Civil Española, Catálogo de la exposición del mismo nombre, organizada por el Museo Nacional de Arte Reyna Sofía, Madrid, Ministerio de Educación y Ciencia, pp. 17-24.

Fusi Aizpúrua, J. P. (2012): Historia mínima de España, Madrid, Turner.

Ibáñez Pareja, E. (2008): Falangismo y propaganda cultural en el «nuevo estado»: la revista Escorial (1940-1950), Granada, Tesis doctorales en Red, http://www.tdx.cat/ handle/10803/77974. (Fecha de consulta: 10/4/2014).

Juan Penalva, J. (2005): La revista Escorial: poesía y poética. Trascendencia literaria de una aventura cultural de la alta posguerra, Alicante, Universitat de Alicante, Colección tesis doctorales de la Universidad de Alicante, http://hdl.handle.net/10045/ 10413. (Fecha de consulta: 15/4/3014). 
Juliá, S. (2002): “¿Falange liberal o intelectuales fascistas?”, Claves de la Razón Práctica, 121, pp. 4-13.

Legendre, M. (1955): Semblanza de España, Madrid, Ediciones y Publicaciones Españolas, S. A. Colección Hispanistas I.

López Gallegos, M. S. (2004): "La política social desarrollada por la Organización Sindical durante el primer franquismo en Zamora 1939-1945. La creación de las Obras Sindicales", Investigaciones Históricas, 24, pp. 214-235.

Manifiesto Editorial (1940): Escorial. Revista de Cultura y Letras, 1, pp. 5-6.

Ministerio de Información y Turismo (1953): Plan Nacional de Turismo, Madrid, Presidencia de Gobierno, Secretaría General para la Ordenación Económica y Social, Edición numerada para estudio y corrección.

Moreno García, A. (2007): Historia del turismo en España, Madrid, Síntesis.

Moreno García, A. (2011): "Fuentes para una historia del turismo español. Fondos documentales del Archivo General de la Administración”, en Actas del X Congreso Internacional de la AEHE, Carmona (Sevilla), Universidad Pablo de Olavide.

Obra Sindical "Educación y Descanso" (1941): Primera Exposición Nacional de Arte. Catálogo General, Madrid, Círculo de Bellas Artes.

Pack, S. D. (2009): La invasión pacífica. Los turistas y la España de Franco, Madrid, Turner.

Pellejero Martínez, C. (2002): "La política turística en la España del siglo xx: una visión general", Historia Contemporánea, 25, pp. 233-265.

Pellejero Martínez, C. (2004): "La política turística en España. Una perspectiva histórica", en J. Aurioles Martín, Las nuevas formas de turismo, Almería, Caja Rural Inter-mediterránea, pp. 268-284.

Pérez Guerra, R. y Ceballos Martin, M. M. (2001): "Relación de disposiciones de Derecho turístico español dictadas a lo largo del siglo xx", Documentación Administrativa, 259-260, pp. 371-589.

Ridruejo, D. (1937): "A nuestros lectores", Vértice, 1, pp. 10, en línea: http://www. magazinesandwar.com/sp_popup.html, (Fecha de consulta: 10/9/2014).

Ridruejo, D. (1938): "Al monasterio de El Escorial", Vértice, 14, pp. 18. en línea: http://www.magazinesandwar.com/sp_popup.html. (Fecha de consulta: 10/9/2014).

Ridruejo, D. (1972): "La vida intelectual española en el primer decenio de la postguerra", Triunfo, XXVII/507 extra, pp. 70-80, en línea: http://hdl.handle.net/10366/ 57258. (Fecha de consulta: 25/7/2014).

Sanz Díaz, C. (2000): "La ciudad residencial de Perlora: espacio de antigüedad territorial, social, ideológico y constructivo", en Actas del Congreso Dos décadas de cultura artística en el franquismo (1936-1956), Granada, Universidad de Granada, pp. 689-701.

Sermet, J. (1954): Image de L Espagne, París, Larousse.

Sevillano Calero, F. (1998): Propaganda y medios de comunicación en el franquismo, 1936-1951, Alicante, Publicaciones de la Universidad de Alicante.

Sevillano Calero, F. (2002): "Propaganda y dirigismo cultural en los inicios del Nuevo Estado”, Pasado y Memoria. Revista de Historia Contemporánea, 1, pp. 81-110. 
Vallejo Pousada, R. (2014): De país turístico rezagado a potencia turística: el turismo en la España de Franco, Documento de Trabajo, n 1419, Asociación Española de Historia Económica, en línea, http://www.aehe.net/2014/03/dt-aehe-1408.pdf, (Fecha de consulta: 17/8/2014).

Velasco González, M. (2004): La política turística. Gobierno y Administración Turística (1952-2004), Valencia, Cañada Blanch.

Velasco González, M. (2005): “¿Existe la política turística? La acción pública en materia de turismo en España (1951- 2004)”, Política y Sociedad, V/42/1, p. 169.

Fecha de recepción: 22 de enero de 2015.

Fecha de aceptación: 20 de mayo de 2015. 